\title{
VOLUMES RATIO OPTIMIZATION IN A CASCADE ANAEROBIC DIGESTION SYSTEM PRODUCING HYDROGEN AND METHANE
}

\begin{abstract}
As focus of humans has turned to renewable energy, the role of anaerobic digestion has started to become economically viable. Reducing the volume of agro-wastes for the generation of gaseous and liquid fractions with energy carriers and valuable products is an enormous challenge. A two-stage anaerobic digestion process consisting of hydrogenic stage followed by methanogenic stage was studied in a laboratory scale. Five simple nonlinear models of this continuous cascade process were studied in order to determine the optimal ratio of working volumes of bioreactors, in view of maximising energy production. This ratio was reported for all adopted models. The optimal ratio (maximal energy production criterion) depends of the adopted mathematical model. Static characteristics of both bioreactors were obtained using Symbolyc toolbox of Matlab. Numerical experiments concerning dynamics of the main variables of both bioreactors for these models using Simulink of Matlab are performed for different step changes of the dilution rate of the first bioreactor, together with the influence of the substrate (acetate) inhibition for one of the models. The value of the constant of inhibition plays an important role on the admissible interval of the dilution rate. The developed idea could serve for optimally designed experiments of anaerobic digestion for production of hydrogen and methane from lignocelluloses wastes (wheat straw) in two phase process.
\end{abstract}

Keywords: anaerobic digestion, two-stage process, mathematical modelling, static characteristics, maximal energy production

\section{Introduction}

Anaerobic digestion (AD) of organic wastes is a very attractive biotechnology mainly in the field of renewable energy sources and biofuels. This approach is very useful for remediation of highly polluted with organics waste waters and municipal effluents. It is known that more than $95 \%$ of the working industrial biogas plants operate with the so called continuously stirred tank bioreactors. In this case the effluent organics is 3-4 times lower than the influent one. AD is able to synchronise human activities with natural cycles. Digestion of organic matter by microorganisms to produce energy and an organic by-product - digestate with possible use in agriculture appears as an effective and low-cost procedure. In traditional $\mathrm{AD}$, hydrogen $\left(\mathrm{H}_{2}\right)$ is not detected as it is consumed immediately in the production of methane $\left(\mathrm{CH}_{4}\right)$ and carbon dioxide $\left(\mathrm{CO}_{2}\right)$ [1, 2]. On the other hand, $\mathrm{H}_{2}$ can be produced separately by engineering the process conditions. Recently, the interest in $\mathrm{H}_{2}$ production through $\mathrm{AD}$ also known as dark fermentative $\mathrm{H}_{2}$ production, has increased [3-5]. The main limitation of dark fermentative $\mathrm{H}_{2}$ production is the rather low energy

\footnotetext{
${ }^{1}$ The Stephan Angeloff Institute of Microbiology, Bulgarian Academy of Sciences, "Acad. G. Bonchev" Str., B1. 26, Sofia 1113, Bulgaria, phone: +359 2 9793188, +359 2 9793614, +359 29793167 , email: elena@microbio.bas.bg, issim@microbio.bas.bg

*Corresponding author: 1kabaivanova@yahoo.com
} 
recovery. In order to completely utilise the organic acids produced during dark fermentation and improve the overall energy conversion efficiency a two-stage AD (TSAD) concept consisting of hydrogenic process, followed by methanogenic process has been suggested [2, 4, 5]. The bottle-neck problems occur in the first stage (production of hydrogen) of the TSAD process. In the fermentation process mixed anaerobic and facultative anaerobic bacterial populations are involved and various metabolic pathways simultaneously act during $\mathrm{H}_{2}$ production, revealing a complexity in action [5]. The main aspects of TSAD have been confirmed with experimental tests, either in batch or in continuous modes, using two feeds representative of organic refuses [6]. Different bioreactors were used as hydrogen or methane production reactors in TSAD. In the known literature more of the TSAD processes are operated manually and the ratio of working volume of CSTR bioreactors is not discussed. In some reports a ratio of ten is accepted without comments. According to Dareioti and Kornaros [7] a TSAD system consisting of two CSTRs operating at mesophilic conditions was used to investigate the effect of hydraulic retention time (the reciprocal value of the dilution rate) on hydrogen and methane production. The ratio of working volumes of bioreactors is equal of eight (without comments). Cavinato et al. [8] performed optimization of TSAD with separately collected municipality biowaste in a pilot scale CSTRs at thermophilic regime using recirculation of the digestate of the second $\mathrm{BR}$ to maintain the $\mathrm{pH}$ in the first $\mathrm{BR}$ at the optimal value. The ratio of working volumes of bioreactors is equal of 3.8. Optimal loading rate is obtained providing maximum $\mathrm{H}_{2}$ and $\mathrm{CH}_{4}$ productions in TSAD of cassava wastewaters using specific thermophilic bioreactors and constant recycling ratio of 1:1 with automatic control of $\mathrm{pH}$ in the hydrogenic bioreactor in the report of Intanoo et al. [9]. The ratio of working volumes of both bioreactors is equal of 6 (without explanation). In the work of Schievano et al. [10] both bio-hydrogen and bio-methane productions are optimised in thermophilic bioreactors regarding two operating parameters (organic loading rate and dilution rate), however, the first bioreactor is running in semi-continuous and the second in batch operation mode, because working volumes of both bioreactors are equal. The first review article by Khan et al. [11] combines the optimization approaches for three possible products from AD - methane, hydrogen and volatile fatty acids (VFA), taking into account different process parameters and types of BR, including acidogenesis and methanogenesis separation in two different BRs. However, the ratio of working volumes of the bioreactors is not included and discussed.

Biogas production is growing in the European energy market and in a few decades it will offer an economical alternative for the production of bio energy [5]. One of the parameters to be optimised for TSAD is the ratio of the working volumes of both bioreactors used. A number of models describing the fermentative hydrogen production and the $\mathrm{AD}$ for methane production are known but only few models of TSAD processes are offered [12]. Although modelling of two-stage anaerobic digestion using the IWA Anaerobic Digestion Model No 1 (ADM1) is presented by Blumensaat and Keller [13], the described AD process is not real TSAD process because methane is obtained from both bioreactors. The volumes of the bioreactors are presented separately but without discussing the ratio between them. Previous experimental studies of co-digestion of mixtures of milk whey and waste activated sludge in a TSAD process and modelling of this processes have been conveyed by us, where methane is obtained from both bioreactors as well as extremum-seeking control design and application for anaerobic digestion processes [14]. 
The aim of this study is to analyse some mathematical models of a continuous process of TSAD with production of hydrogen and methane in a cascade of two CSTRs, in order to find a solution of the very important problem for practice - optimization of the ratio of the working volumes of both bioreactors in view of maximising the energy production. To our knowledge this is the first attempt to theoretically investigate this problem.

\section{Methods}

The application of a TSAD process, including two bioreactors for sequential $\mathrm{H}_{2}$ and $\mathrm{CH}_{4}$ production in CSTRs has been proposed for better process performance and higher energy yields as compared to the traditional one-stage $\mathrm{CH}_{4}$ production process. Laboratory installation was used (Fig. 1).

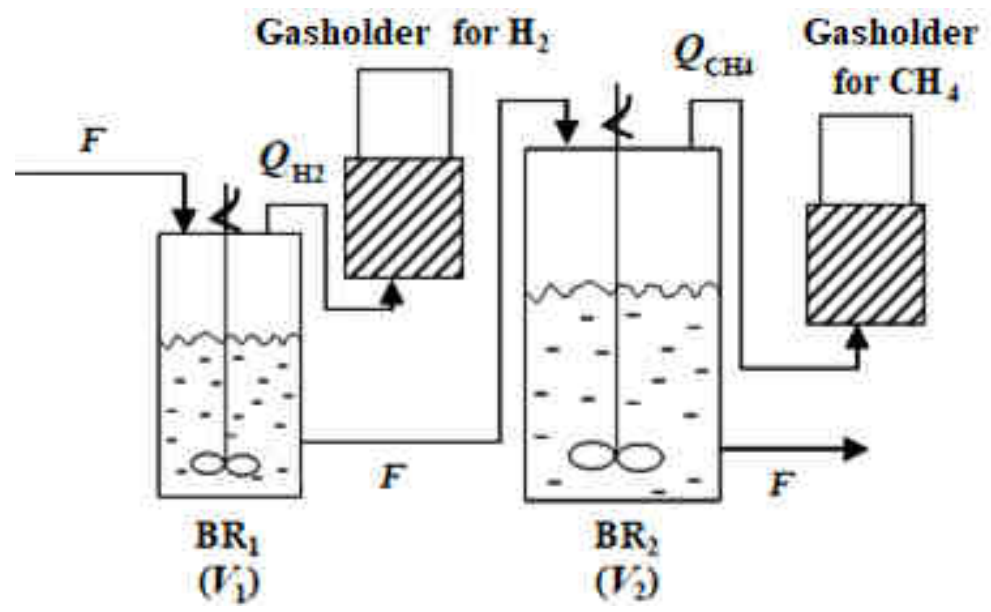

Fig. 1. Two-stage process of $\mathrm{AD}$ with production of hydrogen and methane

By definition for: CSTRs $D_{1}=\frac{F}{V_{1}}$ and $D_{2}=\frac{F}{V_{2}}$. After some transformations it was obtained that: $K=\frac{V_{2}}{V_{1}}=\frac{D_{1}}{D_{2}}$. In the known literature there are no discussions and solutions how to obtain an optimal value of the coefficient $K$. The static input-output characteristics both for hydrogen $Q_{\mathrm{H}_{2}}=f_{1}\left(D_{1}\right)$ and for methane $Q_{\mathrm{CH}_{4}}=f_{2}\left(D_{2}\right)$ flow rates present extrema (maxima) in the admissible range of the control input $\left(D_{1}\right)$ for different values of the main perturbation - $S_{0}^{\text {in }}[12,14,15]$.

The new idea for calculating the optimal ratio of the working volumes of both bioreactors is based on the possibility to assure operating of both bioreactors in the points of maximal biogas (hydrogen and methane) production: $K_{\mathrm{opt}}=\frac{V_{2}}{V_{1}}=\frac{D_{1 \max }}{D_{2 \max }}$. In this case $K$ is optimal in the sense of maximal energy production $\left(Q_{\mathrm{H}_{2}}+Q_{\mathrm{CH}_{4}}=\mathrm{Max}\right)$. 


\section{Results and discussion}

\section{Modelling of the processes for simultaneous production of $\mathrm{H}_{2}$ and $\mathrm{CH}_{4}$}

The application of a TSAD process for sequential $\mathrm{H}_{2}$ and $\mathrm{CH}_{4}$ production in CSTRs has been proposed as a promising technology for better process performance and reaching higher energy yields as compared to the traditional one-stage $\mathrm{CH}_{4}$ production process. It is known that in the two-stage $\mathrm{H}_{2}+\mathrm{CH}_{4}$ system with CSTRs the energy yields are 20-40\% higher compared to the traditional one-stage $\mathrm{CH}_{4}$ production process [4, 5]. Experimental studies in a laboratory scale on AD of lignocellulosic waste (wheat straw) in single and two-stage processes with production of hydrogen through the acidogenic phase and of methane through the methanogenic phase was studied. As a result, the total amount of energy that is produced in the single-stage methanogenic process is $34 \%$ less compared to a two-staged one. This difference comes from both - hydrogen released - about $17 \%$ together with the increased amount of methane - about $13 \%$ [16]. In the TSAD system, relatively fast growing acidogens and $\mathrm{H}_{2}$-producing microorganisms are developed in the first-stage hydrogenic bioreactor $\left(\mathrm{BR}_{1}\right)$ with working volume $V_{1}$ and $\mathrm{pH}$ in the interval 5.0-5.5, operating with dilution rate $D_{1}$. They are involved in the production of acetate, propionate, butyrate and $\mathrm{H}_{2}$ (acidogenesis) and acetate consuming methanogens are eliminated. On the other hand, the slow growing acetogens and methanogens are developed in the second-stage methanogenic bioreactor $\left(\mathrm{BR}_{2}\right)$ with working volume $V_{2}$ and $\mathrm{pH}$ in the interval 6.5-8.5, operating with dilution rate $D_{2}$ in which the produced propionate and butyrate are further converted to acetate (acetogenesis) and after that to $\mathrm{CH}_{4}$ and $\mathrm{CO}_{2}$ (methanogenesis).

The object of our interest was five balance models of the process in CSTRs consisting of some ODEs and algebraic equations as follows:

Equations (1) and (2) present balances of the substrates $\left(S_{0}\right.$ and $\left.S_{1}\right)$ - for example cellulose and cellobiose. Equation (3) describes the dynamics of the biomass (for ex. Clostridium thermocellum) concentration $\left(X_{1}\right)$, equation (4) - dynamics of the product (acetate) formation $\left(A c_{1}\right)$ and the algebraic equation (5) - the flow rate of the hydrogen in the gas phase in $\mathrm{BR}_{1}$. For the specific growth rate of the biomass a Monod type function was adopted (5). Model of the processes without hydrolysis were called MODEL1; Model of the processes with hydrolysis including acetate as an intermediate product, called MODEL2:

- $\mathrm{BR}_{1}$ :

$$
\begin{gathered}
\frac{d S_{0}}{d t}=-D_{1} S_{0}-\beta X_{1} S_{0}+D_{1} Y_{p} S_{0}^{\text {in }} \\
\frac{d S_{1}}{d t}=-D_{1} S_{1}+\beta X_{1} S_{0}-\frac{1}{Y_{1}} \mu_{1} X_{1} \\
\frac{d X_{1}}{d t}=\mu_{1} X_{1}-D_{1} X_{1} \\
\frac{d A c_{1}}{d t}=\frac{1}{Y_{2}} \mu_{1} X_{1}-D_{1} A c_{1} \\
Q_{\mathrm{H}_{2}}=Y_{\mathrm{H}_{2}} \mu_{1} X_{1}
\end{gathered}
$$




$$
\mu_{1}=\frac{\mu_{1 \max } S_{1}}{K_{\mathrm{S} 1}+S_{1}}
$$

- $\mathrm{BR}_{2}$ :

$$
\begin{gathered}
\frac{d X_{2}}{d t}=\mu_{2} X_{2}-D_{2} X_{2} \\
\frac{d A c_{2}}{d t}=-\frac{1}{Y_{3}} \mu_{2} X_{2}+D_{2}\left(A c_{1}-A c_{2}\right) \\
Q_{\mathrm{CH}_{4}}=Y_{\mathrm{CH}_{4}} \mu_{2} X_{2} \\
\mu_{2}=\frac{\mu_{2 \max _{2}} A c_{2}}{K_{\mathrm{S} 2}+A c_{2}}
\end{gathered}
$$

Model of the processes with hydrolysis including acetate as an intermediate product and substrate inhibition is called MODEL3. This model is the same as MODEL2 with the unique difference in the specific growth rate of methanogenic bacteria equation for $\mathrm{BR}_{2}$, including substrate inhibition [17]:

$$
\mu_{2}=\frac{\mu_{2 \max } A c_{2}}{K_{\mathrm{S} 2}+A c_{2}+A c_{2}^{2} / K_{\mathrm{i}}}
$$

Model of the processes with hydrolysis including acetate and propionate as intermediate products is called MODEL4:

- $\mathrm{BR}_{1}$ :

$$
\begin{gathered}
\frac{d S_{0}}{d t}=-D_{1} S_{0}-\beta X_{1} S_{0}+D_{1} Y_{p} S_{0}^{\text {in }} \\
\frac{d S_{1}}{d t}=-D_{1} S_{1}+\beta X_{1} S_{0}-\frac{\mu_{1} X_{1}}{Y_{1}} \\
\frac{d X_{1}}{d t}=\mu_{1} X_{1}-D_{1} X_{1} \\
\frac{d \operatorname{Pr}_{1}}{d t}=\frac{\mu_{1} X_{1}}{Y_{\mathrm{Pr} 1}}-D_{1} \operatorname{Pr}_{1} \\
\frac{d A c_{1}}{d t}=\frac{\mu_{1} X_{1}}{Y_{\mathrm{Ac} 1}}-D_{1} A c_{1} \\
Q_{\mathrm{H}_{2}}=Y_{\mathrm{H}_{2}} \mu_{1} X_{1} \\
\mu_{1}=\frac{\mu_{1 \max } S_{1}}{K_{\mathrm{S} 1}+S_{1}}
\end{gathered}
$$

- $\mathrm{BR}_{2}$ :

$$
\frac{d X_{\mathrm{Pr}}}{d t}=\mu_{\mathrm{Pr}} X_{\mathrm{Pr}}-D_{2} X_{\mathrm{Pr}}
$$




$$
\begin{gathered}
\frac{d \operatorname{Pr}_{2}}{d t}=-\frac{\mu_{\mathrm{Pr}} X_{\mathrm{Pr}}}{Y_{\mathrm{Pr} 2}}+D_{2}\left(\operatorname{Pr}_{1}-\operatorname{Pr}_{2}\right) \\
\frac{d X_{\mathrm{Ac}}}{d t}=\mu_{\mathrm{Ac}} X_{\mathrm{Ac}}-D_{2} X_{\mathrm{Ac}} \\
\frac{d A c_{2}}{d t}=-\frac{\mu_{\mathrm{Ac}} X_{\mathrm{Ac}}}{Y_{\mathrm{Ac} 2}}+\frac{\mu_{\mathrm{Pr}} X_{\mathrm{Pr}}}{Y_{\mathrm{Pr} 2}}+D_{2}\left(A c_{1}-A c_{2}\right) \\
Q_{\mathrm{CH}_{4}}=Y_{\mathrm{CH}_{4}} \mu_{\mathrm{Ac}} X_{\mathrm{Ac}} \\
\mu_{\mathrm{Pr}}=\frac{\mu_{\mathrm{Pr} \max } \operatorname{Pr}_{2}}{K_{\mathrm{SPr}}+\operatorname{Pr}_{2}} \\
\mu_{\mathrm{Ac}}=\frac{\mu_{\mathrm{Acmax}} A c_{2}}{K_{\mathrm{SAc}}+A c_{2}}
\end{gathered}
$$

Models 2, 3 and 4 are developed from a methodological point of view - to prove that the adopted approach for obtaining the optimal ratio of working volumes is admissible for different kind of models.

\begin{tabular}{|c|c|}
\hline Notation & Definition \\
\hline$t$ & Time $[\mathrm{h}]$ \\
\hline$D_{1}$ & Dilution rate for $\mathrm{BR}_{1}\left[\mathrm{~h}^{-1}\right]$ \\
\hline$D_{1 \max }$ & Value of $D_{1}$ corresponding of $Q_{\mathrm{H}_{2 \max }}$ \\
\hline$D_{1 \text { sub }}$ & Admissible value of $D_{1}$ (without wash-out of acidogenic bacteria) \\
\hline$D_{2}$ & Dilution rate for $\mathrm{BR}_{2}\left[\mathrm{~h}^{-1}\right]$ \\
\hline$D_{2 \max }$ & Value of $D_{2}$ corresponding of $Q_{\mathrm{CH}_{4 \max }}$ \\
\hline$D_{2 \text { sub }}$ & Admissible value of $D_{2}$ (without wash-out of methanogenic bacteria) \\
\hline$S_{0}^{\text {in }}$ & Inlet cellulose concentration in $\mathrm{BR}_{1}[\mathrm{~g} / \mathrm{L}]$ \\
\hline$S_{0}$ & Cellulose concentration $[\mathrm{g} / \mathrm{L}]$ \\
\hline$S_{1}$ & Cellobiose substrate concentration $[\mathrm{g} / \mathrm{L}]$ \\
\hline$X_{1}$ & Acidogenic bacteria concentration $[\mathrm{g} / \mathrm{L}]$ \\
\hline$X_{2}$ & Methanogenic bacteria concentration $[\mathrm{g} / \mathrm{L}]$ \\
\hline$X_{\operatorname{Pr}}$ & Propionate degrading bacteria concentration $[\mathrm{g} / \mathrm{L}]$ \\
\hline$X_{\mathrm{Ac}}$ & Methanogenic bacteria concentration $[\mathrm{g} / \mathrm{L}]$ \\
\hline$\mu_{1}$ & Specific growth rate for acidogenic bacteria $\left[\mathrm{h}^{-1}\right]$ \\
\hline$\mu_{2}$ & Specific growth rate for methanogenic bacteria $\left[\mathrm{h}^{-1}\right]$ \\
\hline$\mu_{\mathrm{Pr}}$ & Specific growth rate for propionate degrading bacteria $\left[\mathrm{h}^{-1}\right]$ \\
\hline$\mu_{\mathrm{Ac}}$ & Specific growth rate for methanogenic bacteria $\left[\mathrm{h}^{-1}\right]$ \\
\hline
\end{tabular}

Model of the processes with hydrolysis including acetate, propionate and butyrate as intermediate products [18] is called MODEL5. The definitions of the model variables and parameters in the equations (1)-(25) are given in Tables 1 and 2.

Table 1

Model variables 


\begin{tabular}{|c|c|}
\hline VFA & Volatile fatty acids concentration \\
\hline $\operatorname{Pr}_{1}, \mathrm{Pr}_{2}$ & Propionate concentration $[\mathrm{g} / \mathrm{L}]$ \\
\hline$A c_{1}, A c_{2}$ & Acetate concentration $[\mathrm{g} / \mathrm{L}]$ \\
\hline$A c_{1 \max }$ & The value of $A c_{1}$, corresponding of $D_{1 \max }$ in $\mathrm{BR}_{1}$ \\
\hline$Q_{\mathrm{H}_{2}}$ & Hydrogen flow rate $[\mathrm{L} / \mathrm{h}]$ \\
\hline$Q_{\mathrm{H}_{\text {max }}}$ & Maximal value of $Q_{\mathrm{H}_{2}}$ \\
\hline$Q_{\mathrm{CH}_{4}}$ & Methane flow rate $[\mathrm{L} / \mathrm{h}]$ \\
\hline$Q_{\mathrm{CH}_{\text {max }}}$ & Maximal value of $Q_{\mathrm{CH}_{4}}$ \\
\hline$V_{1}, V_{2}$ & Working volumes of $\mathrm{BR} \mathrm{R}_{1}$ and $\mathrm{BR}_{2}[\mathrm{~L}]$ \\
\hline
\end{tabular}

Model parameters

\begin{tabular}{|c|c|c|}
\hline Notation & Value & Definition \\
\hline$\mu_{1 \max }$ & 0.568 & Maximum specific growth rate for acidogenic bacteria $\left[\mathrm{h}^{-1}\right]$ \\
\hline$\mu_{2 \max }$ & 0.0083 & Maximum specific growth rate for methanogenic bacteria $\left[\mathrm{h}^{-1}\right]$ \\
\hline$\mu_{\text {Prmax }}$ & 0.05 & Maximum specific growth rate for propionate degrading bacteria $\left[\mathrm{h}^{-1}\right]$ \\
\hline$\mu_{\mathrm{Acmax}}$ & 0.025 & Maximum specific growth rate for methanogenic bacteria $\left[\mathrm{h}^{-1}\right]$ \\
\hline$K_{S 1}$ & 3.914 & Saturation coefficient for acidogenic bacteria $[\mathrm{g} / \mathrm{L}]$ \\
\hline$K_{S 2}$ & 0.22 & Saturation coefficient for acetogenic bacteria $[\mathrm{g} / \mathrm{L}]$ \\
\hline$K_{\mathrm{SPr}}$ & 0.22 & Saturation coefficient for propionate $[\mathrm{g} / \mathrm{L}]$ \\
\hline$K_{\mathrm{SAc}}$ & 0.8 & Saturation coefficient for acetate $[\mathrm{g} / \mathrm{L}]$ \\
\hline$K_{\mathrm{i}}$ & 10 & Inhibition constant $[\mathrm{g} / \mathrm{L}]$ \\
\hline$K_{\mathrm{i}}^{\mathrm{inf}}$ & - & A lower bound of $K_{\mathrm{i}}$ \\
\hline$\beta$ & 1 & Coefficient of biodegradability $[\mathrm{L} /(\mathrm{g} \cdot \mathrm{h})]$ \\
\hline$Y_{\mathrm{p}}$ & 1 & Coefficient $[-]$ \\
\hline$Y_{1}$ & 0.08 & Yield coefficient for acidogenic bacteria [-] \\
\hline$Y_{2}$ & 1 & Yield coefficient for acetogenic bacteria [-] \\
\hline$Y_{3}$ & 0.24 & Yield coefficient for methanogenic bacteria [-] \\
\hline$Y_{\mathrm{Pr}_{1}}$ & 2.1 & Yield coefficient for propionate [-] \\
\hline$Y_{\mathrm{Ac}_{1}}$ & 1.1 & Yield coefficient for acetate [-] \\
\hline$Y_{\mathrm{Pr}_{2}}$ & 1.5 & Yield coefficient for propionate [-] \\
\hline$Y_{\mathrm{Ac}_{2}}$ & 0.5 & Yield coefficient for acetate $[-]$ \\
\hline$Y_{\mathrm{H}_{2}}$ & 1 & Yield coefficient for hydrogen $[\mathrm{L} / \mathrm{g}]$ \\
\hline$Y_{\mathrm{CH}_{4}}$ & 142 & Yield coefficient for methane $[\mathrm{L} / \mathrm{g}]$ \\
\hline$K$ & - & Ratio of working volumes of bioreactors [-] \\
\hline$K_{\text {opt }}$ & - & Optimal ratio of working volumes of bioreactors [-] \\
\hline
\end{tabular}

Numerical experiments concerning dynamics of the main variables of both bioreactors for all above presented models using Simulink of Matlab are performed for different step changes of the control variable $D_{1}\left(D_{2}\right)$. Some results concerning the dynamics of the flow rates of hydrogen $Q_{\mathrm{H}_{2}}$ and methane $Q_{\mathrm{CH}_{4}}$ for step changes of the control variable $D_{1}\left(D_{2}\right)$ 
are presented in Table 3 using MODEL2 $(K=56.4)$ are shown on Figures 2 and 3. Figure 2 for $\mathrm{BR}_{1}$ is plotted with 20 times shorter periods for visualization.

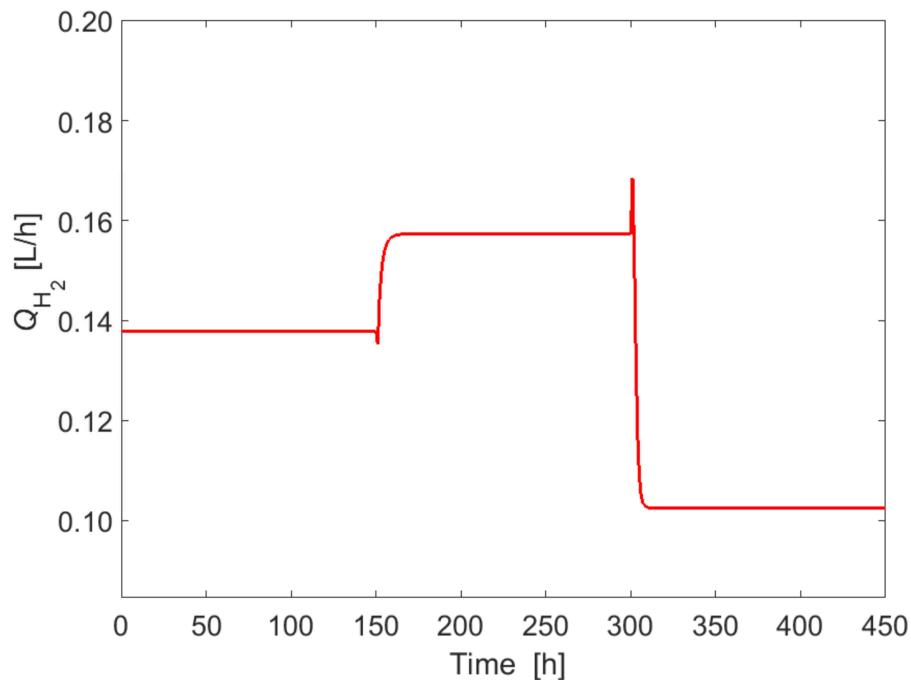

Fig. 2. Dynamics of the hydrogen flow rate $Q_{\mathrm{H}_{2}}\left(\mathrm{BR}_{1}\right)$ for step changes of the control variable $D_{1}$ presented in Table 3

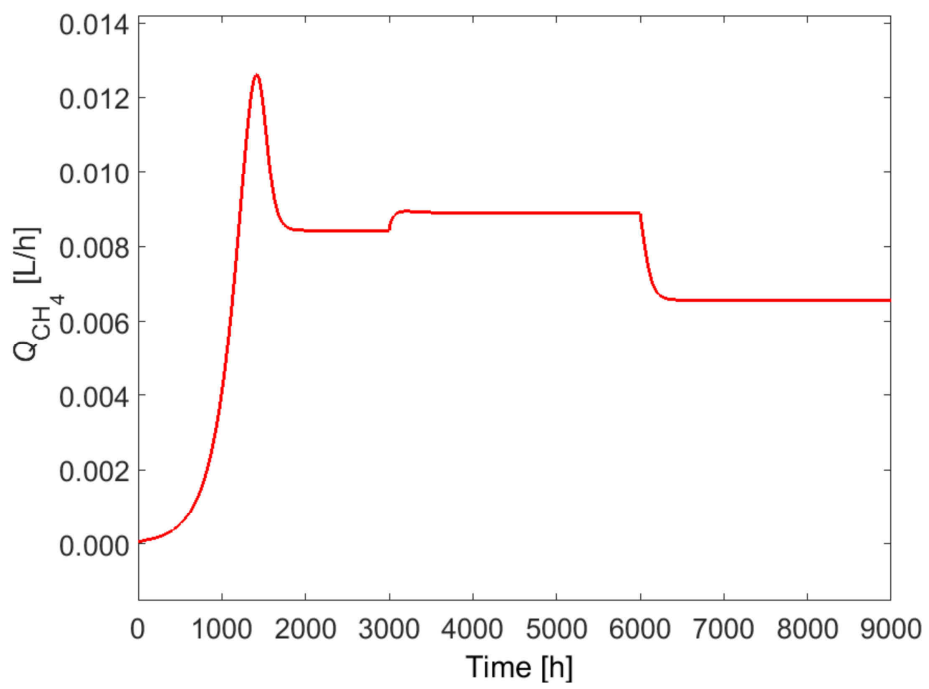

Fig. 3. Dynamics of the methane flow rate $Q_{\mathrm{CH}_{4}}\left(\mathrm{BR}_{2}\right)$ for step changes of the control variable $D_{2}$ presented in Table 3

The simulation results from Figures 2 and 3 illustrate the model validity. 
Step changes of $D_{1}\left(D_{2}=D_{1} / 67\right)$

\begin{tabular}{|c|c|c|c|}
\hline Hour & $\mathbf{0 - 1 4 9}(\mathbf{2 9 9 9})$ & $\mathbf{1 5 0}(\mathbf{3 0 0 0})-\mathbf{2 9 9}(\mathbf{5 9 9 9})$ & $\mathbf{3 0 0}(\mathbf{6 0 0 0})-\mathbf{4 5 0}(\mathbf{9 0 0 0})$ \\
\hline$D_{1}\left[\mathrm{~h}^{-1}\right]$ & 0.15 & 0.2 & 0.1 \\
\hline
\end{tabular}

\section{Static characteristics of $B R_{1}$ and $B R_{2}$}

Transforming the equations of the balance models using Symbolyc toolbox of Matlab, some algebraic equations called static characteristics of both bioreactors were obtained. They represent dependencies of the main process variables from the dilution rates. The static characteristics for MODEL1 and for MODEL5 are shown in Chorukova and Simeonov [12].

- Static characteristics for MODEL2, $\mathrm{BR}_{1}$

$$
\begin{gathered}
S_{0}=S_{0}\left(D_{1}, S_{0}^{i n}\right)=\frac{P_{1}-P_{2}}{Y_{1}} \\
S_{1}=S_{1}\left(D_{1}\right)=\frac{K_{S 1} D_{1}}{\mu_{1 \max }-D_{1}} \\
X_{1}=X_{1}\left(D_{1}, S_{0}^{i n}\right)=P_{1}+P_{2} \\
A c_{1}=A c_{1}\left(D_{1}, S_{0}^{i n}\right)=\frac{P_{1}+P_{2}}{Y_{2}} \\
Q_{\mathrm{H}_{2}}=Q_{\mathrm{H}_{2}}\left(D_{1}, S_{0}^{\text {in }}\right)=Y_{\mathrm{H}_{2}} D_{1}\left(P_{1}+P_{2}\right) \\
\mu_{1 \max } S_{0}^{\text {in }} Y_{1} Y_{p}-K_{S 1} Y_{1} D_{1}-S_{0}^{\text {in }} Y_{1} Y_{p} D_{1} \\
2\left(\mu_{1 \max }-D_{1}\right) \\
P_{1} \\
P_{3}=D_{1}^{4}-2 \mu_{1 \max } D_{1}^{3}+2 \beta K_{S 1} Y_{1} D_{1}^{3}-2 \beta S_{0}^{i n} Y_{1} Y_{p} D_{1}^{3}+\beta^{2} K_{S 1}^{2} Y_{1}^{2} D_{1}^{2}+ \\
+2 \beta^{2} K_{S 1} S_{0}^{i n} Y_{1}^{2} Y_{p} D_{1}^{2}+\beta^{2} S_{0}^{i n 2} Y_{1}^{2} Y_{p}^{2} D_{1}^{2}-2 \beta K_{S 1} \mu_{1 \max } Y_{1} D_{1}^{2}+ \\
+4 \beta \mu_{1 \max } S_{0}^{i n} Y_{1} Y_{p} D_{1}^{2}+\mu_{1 \max }^{2} D_{1}^{2}-2 \beta^{2} K_{S 1} \mu_{1 \max } S_{0}^{i n} Y_{1}^{2} Y_{p} D_{1}-\sqrt{P_{3}} \\
-2 \beta^{2} \mu_{1 \max } S_{0}^{i n 2} Y_{1}^{2} Y_{p}^{2} D_{1}-2 \beta \mu_{1 \max }^{2} S_{0}^{i n} Y_{1} Y_{p} D_{1}+\beta^{2} \mu_{1 \max }^{2} S_{0}^{i n 2} Y_{1}^{2} Y_{p}^{2}
\end{gathered}
$$

- Static characteristics for MODEL2, $\mathrm{BR}_{2}$ (the same as for MODEL1, $\mathrm{BR}_{2}$ ):

$$
\begin{gathered}
A c_{2}=A c_{2}\left(D_{2}\right)=\frac{D_{2} K_{S 2}}{\mu_{2 \max }-D_{2}} \\
X_{2}=X_{2}\left(D_{1}, S_{0}^{\text {in }}, D_{2}\right)=Y_{3}\left(A c_{1}-\frac{D_{2} K_{S 2}}{\mu_{2 \max }-D_{2}}\right)
\end{gathered}
$$




$$
Q_{\mathrm{CH}_{4}}=Q_{\mathrm{CH}_{4}}\left(D_{1}, S_{0}^{\text {in }}, D_{2}\right)=Y_{3} Y_{\mathrm{CH}_{4}} D_{2}\left(A c_{1}-\frac{D_{2} K_{\mathrm{S} 2}}{\mu_{2 \max }-D_{2}}\right)
$$

- Static characteristics for MODEL3, $\mathrm{BR}_{1}$ are the same as for MODEL2, $\mathrm{BR}_{1}$.

- Static characteristics for MODEL3, $\mathrm{BR}_{2}$ (with acetate inhibition on the methanogenic bacterial population):

$$
\begin{gathered}
A c_{2}=A c_{2}\left(D_{2}\right)=\frac{P_{4}-D_{2} K_{i}+K_{i} \mu_{2 \max }}{2 D_{2}} \\
X_{2}=X_{2}\left(D_{1}, S_{0}^{\text {in }}, D_{2}\right)=\frac{-Y_{3} P_{4}+2 D_{2}\left(P_{1}+P_{2}\right) / Y_{2}+D_{2} K_{i}-K_{i} \mu_{2 \max }}{2 D_{2}} \\
Q_{\mathrm{CH}_{4}}=Q_{\mathrm{CH}_{4}}\left(D_{1}, S_{0}^{\text {in }}, D_{2}\right)=\frac{-Y_{3} Y_{\mathrm{CH}_{4}} P_{4}+2 D_{2}\left(P_{1}+P_{2}\right) / Y_{2}+D_{2} K_{i}-K_{i} \mu_{2 \max }}{2} \\
P_{4}=\sqrt{K_{i}\left(D_{2}^{2} K_{i}-4 D_{2}^{2} K_{S 2}+K_{i} \mu_{2 \max }^{2}-2 D_{2} K_{i} \mu_{2 \max }\right)}
\end{gathered}
$$

- Static characteristics for MODEL4, $\mathrm{BR}_{1}$ are the same as for MODEL2, $\mathrm{BR}_{1}$, with the only difference for:

$$
\begin{gathered}
\operatorname{Pr}_{1}=\operatorname{Pr}_{1}\left(D_{1}, S_{0}^{\text {in }}\right)=\frac{P_{1}+P_{2}}{Y_{\mathrm{Pr}_{1}}} \\
A c_{1}=A c_{1}\left(D_{1}, S_{0}^{\text {in }}\right)=\frac{P_{1}+P_{2}}{Y_{A c_{1}}}
\end{gathered}
$$

- $\quad$ Static characteristics for MODEL4, $\mathrm{BR}_{2}$ :

$$
\begin{gathered}
X_{\mathrm{Pr}}=X_{\mathrm{Pr}_{2}}\left(D_{2}, \operatorname{Pr}_{1}\right)=Y_{\mathrm{Pr}_{2}}\left(\operatorname{Pr}_{1}-\frac{D_{2} K_{S \operatorname{Pr}}}{\mu_{\mathrm{Pr} \max }-D_{2}}\right) \\
\operatorname{Pr}_{2}=\operatorname{Pr}_{2}\left(D_{2}\right)=\frac{D_{2} K_{S \operatorname{Pr}}}{\mu_{\mathrm{Pr} \max }-D_{2}} \\
A c_{2}=A c_{2}\left(D_{2}\right)=\frac{D_{2} K_{S A c}}{\mu_{\mathrm{Acmax}}-D_{2}} \\
X_{A c}=X_{A c}\left(D_{2}, \operatorname{Pr}_{1}, A c_{1}\right)=\frac{Y_{A c_{2}} P_{5}}{\left(\mu_{\mathrm{Pr} \max }-D_{2}\right)\left(\mu_{\mathrm{Acmax}}-D_{2}\right)} \\
Q_{\mathrm{CH}_{4}}=Q_{\mathrm{CH}_{4}}\left(D_{2}, \operatorname{Pr}_{1}, A c_{1}\right)=\frac{Y_{\mathrm{Ac}} Y_{\mathrm{CH}} D_{2} P_{5}}{\left(\mu_{\mathrm{Pr} \max }-D_{2}\right)\left(\mu_{\mathrm{Acmax}}-D_{2}\right)} \\
P_{5}=\operatorname{Pr}_{1} D_{2}^{2}+A c_{1} D_{2}^{2}+K_{S \mathrm{Pr}} D_{2}^{2}+K_{S A c} D_{2}^{2}-\operatorname{Pr}_{1} \mu_{\mathrm{Pr} \max } D_{2}- \\
-\operatorname{Pr}_{1} \mu_{\mathrm{Acmax}} D_{2}-A c_{1} \mu_{\mathrm{Pr} \max } D_{2}-A c_{1} \mu_{\mathrm{Acmax}} D_{2}+\operatorname{Pr}_{1} \mu_{\mathrm{Pr} \max } \mu_{\mathrm{Acmax}}+ \\
+A c_{1} \mu_{\mathrm{Pr} \max } \mu_{\mathrm{Acmax}}-K_{S \mathrm{Pr}} \mu_{\mathrm{Acmax}} D_{2}-K_{\mathrm{SAc}} \mu_{\mathrm{Pr}_{\max }} D_{2}
\end{gathered}
$$


- Static characteristics $Q_{\mathrm{H}_{2}}=f\left(D_{1}\right)$ and $Q_{\mathrm{CH}_{4}}=f\left(D_{2}\right)$ for different values of $S_{0}^{\text {in }}$ in the case of MODEL5 [19] are presented on Figure 4. The concentration of influent organic matter is taken as the main external disturbance, which is reflected in the models. Its change leads to a shift of the corresponding static characteristics, without changing their nature, but of course the value of the maximum also changes.

a)

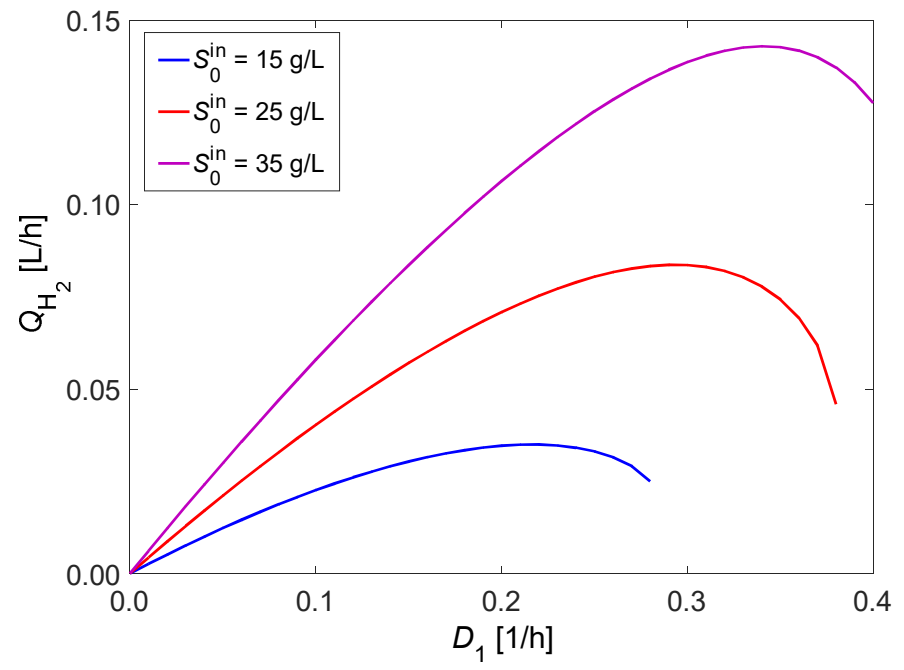

b)

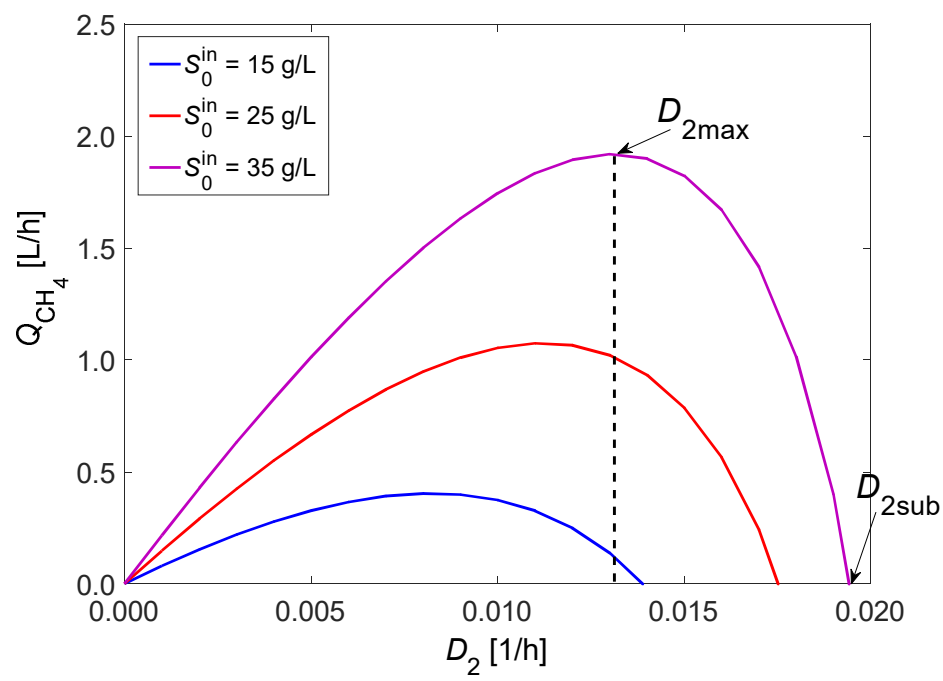

Fig. 4. Static characteristics for different values of $S_{0}^{\text {in }}$ in the case of MODEL5: a) hydrogen yield in dependence of dilution rate in $\mathrm{BR}_{1}$ and $\mathrm{b}$ ) methane yield in dependence of dilution rate in $\mathrm{BR}_{2}$ 
Analysing static characteristics it is evident that all static characteristics are nonlinear. Most static characteristics are depending from inlet substrate concentration in $\operatorname{BR}_{1}\left(S_{0}^{\text {in }}\right)$. Only the static characteristics of the hydrogen flow rate and methane flow rate presents extremums (maxima) for both of them in the admissible range of the control input $\left(D_{1}\right)$ for different values of the main perturbation $-S_{0}^{\text {in }}$. That is a good possibility for realization of extremum-seeking control algorithms [16]. It is known that reactions rates in $\mathrm{BR}_{1}$ are much faster that these in $\mathrm{BR}_{2}$. To optimise the functioning of the two-stage process in continuous operation mode, the working volume of $\mathrm{BR}_{2}$ must be bigger than that of $\mathrm{BR}_{1}$. But how many times? We could propose the following idea: We suppose that $\mathrm{BR}_{1}$ is working in the optimal point for maximising the hydrogen production and $\mathrm{BR}_{2}$, as well, is working in the optimal point for maximising the methane production. To reach this situation it is sufficiently that:

$$
K=\frac{V_{2}}{V_{1}}=\frac{D_{1 \max }}{D_{2 \max }}
$$

Calculating the coefficient $K$ was done as follows: First, the static characteristics of $Q_{\mathrm{H}_{2}}$ and $Q_{\mathrm{CH}_{4}}$ for different values of $S_{0}^{i n}$ and varying in appropriate intervals $D_{1}$ and $D_{2}$ using model parameters shown in nomenclature were calculated. After that $D_{1 \max }$ and $D_{2 \max }$ were taken down for corresponding $Q_{\mathrm{H}_{2}}^{\max }$ and $Q_{\mathrm{CH}_{4}}^{\max }$. Using this values $K$ was calculated. In this case it will be possible to obtain maximum energy (maximal energy production criterion). Our studies show that the coefficient $K$ depends on $S_{0}^{i n}$. That is why the characteristic $K=f\left(S_{0}^{i n}\right)$, determining the ratio of the working volumes of the two bioreactors, was obtained using (49) for different values of $S_{0}^{i n}$. For all investigated models and $S_{0}^{\text {in }} \in(15-35) \mathrm{g} / \mathrm{L}$, characteristics $K=f\left(S_{0}^{\text {in }}\right)$ are presented on Figure 5 and in Table 4. The optimal ratio of the working volumes of the two bioreactors is approximately the same at different values of $S_{0}^{i n}$, which results from the very way of its analytical determination.

Table 4

Values of $\mathrm{K}[-]$

\begin{tabular}{|c|c|c|c|c|c|c|}
\hline$S_{0}^{\text {in }}$ & $\mathbf{1 5}[\mathbf{g} / \mathbf{L}]$ & $\mathbf{2 0}[\mathbf{g} / \mathbf{L}]$ & $\mathbf{2 5}[\mathbf{g} / \mathbf{L}]$ & $\mathbf{3 0}[\mathbf{g} / \mathbf{L}]$ & $\mathbf{3 5}[\mathbf{g} / \mathbf{L}]$ & Average \\
\hline MODEL1 & 68.89 & 68.00 & 67.92 & 66.96 & 67.24 & 67.8 \\
\hline MODEL2 & 50.00 & 54.17 & 57.84 & 59.26 & 60.71 & 56.4 \\
\hline MODEL3 & 45.74 & 52.00 & 55.66 & 58.18 & 60.71 & 54.5 \\
\hline MODEL4 & 26.88 & 27.37 & 28.10 & 26.67 & 27.20 & 27.2 \\
\hline MODEL5 & 27.50 & 26.00 & 26.36 & 26.67 & 26.15 & 26.5 \\
\hline
\end{tabular}




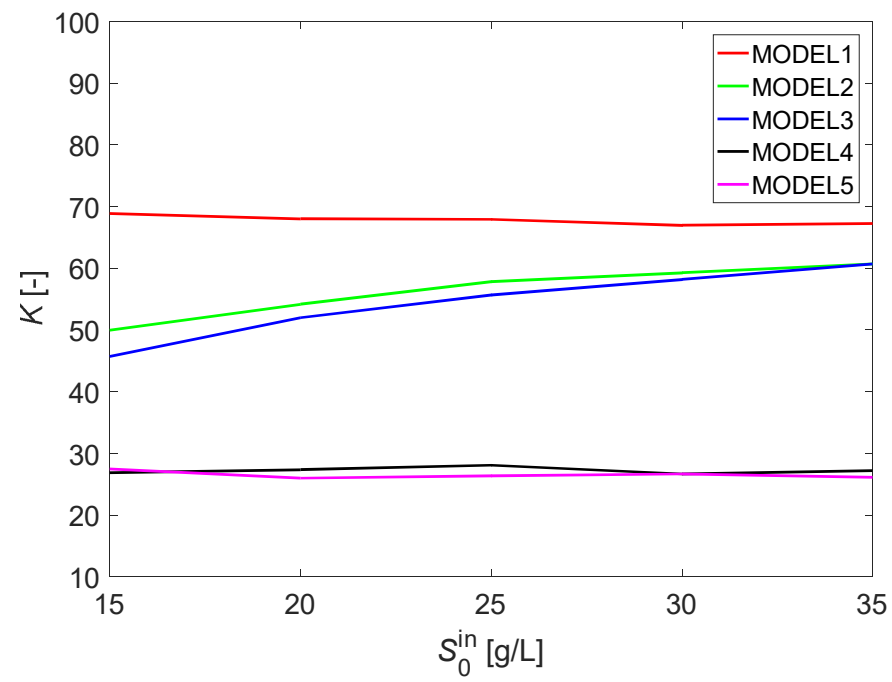

Fig. 5. Characteristic $K=f\left(S_{0}^{\text {in }}\right)$ for all studies models

The initial conditions in relation to the main variables (concentrations of substrates and microorganisms) play a role only at the start of the process (as a batch process). In models of processes of continuous type, each value of the control variable $D$ corresponds to certain values of all other variables, which are coordinates of the corresponding steady state of the process and appear to be initial values at the next change of $D$. The stability of these steady states had already been shown in our previous work [17]. The important point is that in the area of the admissible range of control variable, which always includes the corresponding maximum, the equilibrium states are always stable. In the area of the permissible range of the control variable, which always includes the corresponding maximum, the equilibrium states are always stable. The optimal ratio of the working volumes of the two bioreactors is approximately the same at different values of $S_{0}^{i n}$, which results from the very way of its analytical determination.

Finally, for each model $K$ may be accepted as a constant equal of the average value. A theoretical study was performed for the influence of the substrate (acetate) inhibition (MODEL 3) on the above developed idea. Obtained results show that the value of the constant of inhibition $K_{i}$ plays an important role on the admissible interval of the dilution rate $D_{2}$. The key values of the dilution rate $D_{2}$ (max and sub) as a function of the constant of inhibition for three values of $S_{0}^{i n}$ are shown on Figures 6-8. The conclusion from these figures is that there exists a lower bound for $K_{i}=K_{i}^{\mathrm{inf}}$ at which $D_{2 \max }=D_{2 \text { sub }}$ (for the existing of maxima of $Q_{\mathrm{CH}_{4}}$ ). In Table 5 the calculated values of $K_{i}^{\text {inf }}$ for different $S_{0}^{i n}$ are shown. 
Values of $K_{i}^{\text {inf }}$ for different $S_{0}^{\text {in }}$

\begin{tabular}{|c|c|c|c|c|c|}
\hline$S_{0}^{\text {in }}$ & $\mathbf{1 5}[\mathbf{g} / \mathbf{L}]$ & $\mathbf{2 0}[\mathbf{g} / \mathbf{L}]$ & $\mathbf{2 5}[\mathbf{g} / \mathbf{L}]$ & $\mathbf{3 0}[\mathbf{g} / \mathbf{L}]$ & $\mathbf{3 5}[\mathbf{g} / \mathbf{L}]$ \\
\hline$K_{i}^{\text {inf }}$ & 1.1 & 1.9 & 2.9 & 4.1 & 5.4 \\
\hline
\end{tabular}

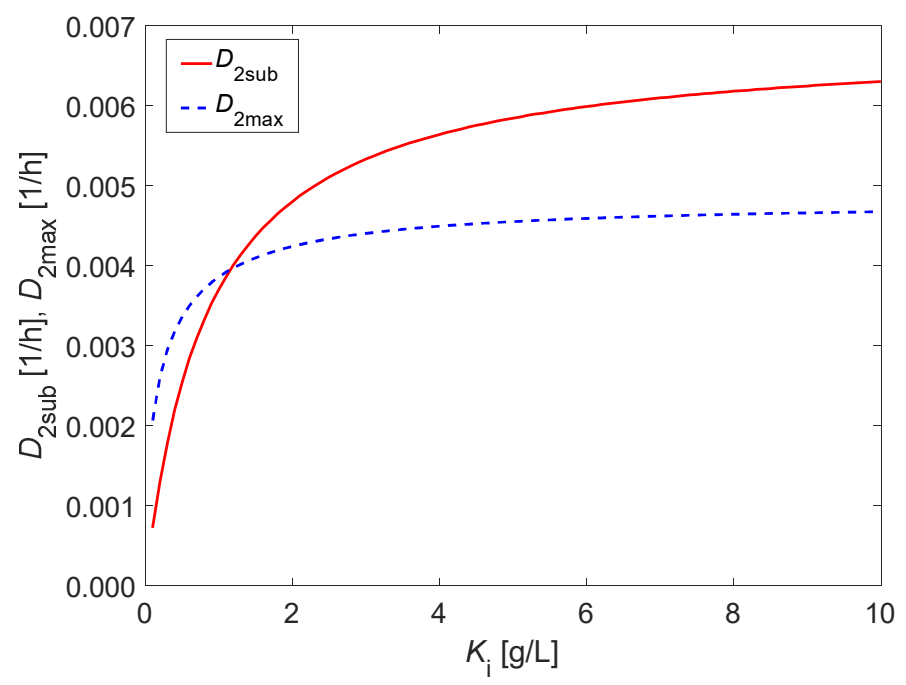

Fig. 6. $D_{2 \text { sub }}$ and $D_{2 \max }$ as a function of $K_{i}$ for $S_{0}^{i n}=15 \mathrm{~g} / \mathrm{L}$

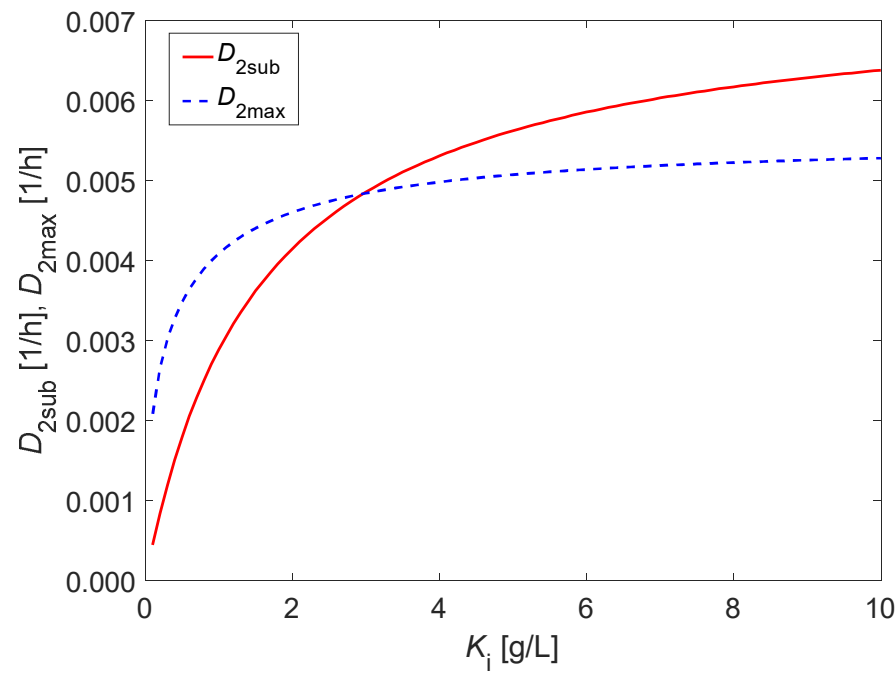

Fig. 7. $D_{2 \text { sub }}$ and $D_{2 \max }$ as a function of $K_{i}$ for $S_{0}^{i n}=25 \mathrm{~g} / \mathrm{L}$ 


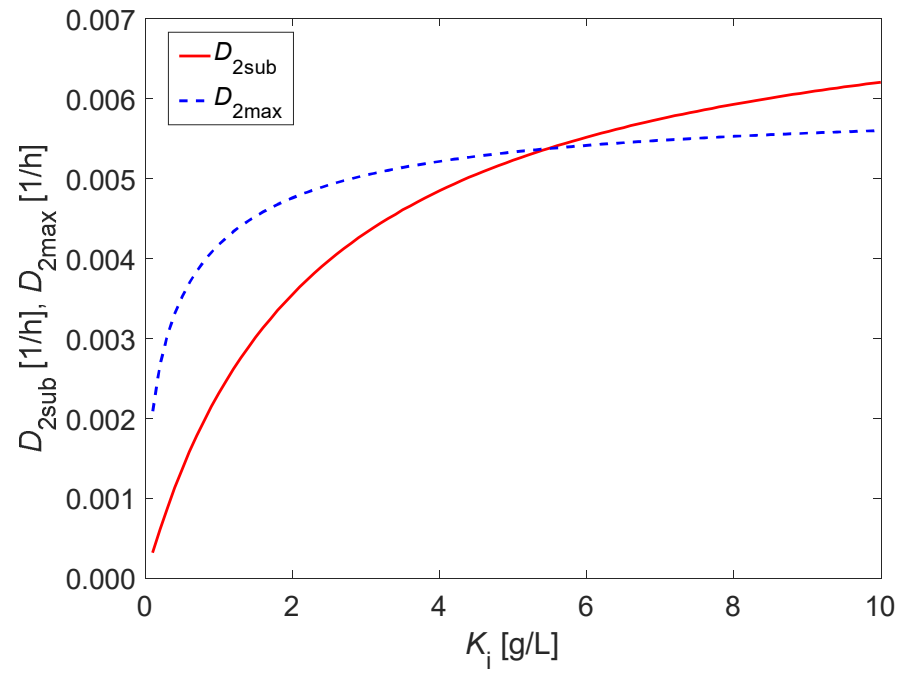

Fig. 8. $D_{2 \text { sub }}$ and $D_{2 \max }$ as a function of $K_{i}$ for $S_{0}^{i n}=35 \mathrm{~g} / \mathrm{L}$

As an illustration of the above presented theoretical results the curves depicting $D_{2 \text { sub }}$ and $D_{2 \max }$ as a function of $A c_{1 \max }$ are presented on Figure 9. $A c_{1}$ is the concentration of acetate in the effluent of $\mathrm{BR}_{1}$ and in the influent of $\mathrm{BR}_{2}$, respectively. From equations (29) to (33) it is evident that $A c_{1}$ is a function of $S_{0}^{i n}$ and $D_{1} . A c_{1 \max }$ is the value corresponding of $D_{1 \max }$ in $\mathrm{BR}_{1}$. Figure 9 illustrates that $D_{2 \max }$ is in the admissible interval for all studied values of the inlet concentration of $S_{0}^{\text {in }}$.

Another conclusion from our theoretical study is that the maximal value of $Q_{\mathrm{CH}_{4}}$ in the case of existence of substrate (acetate) inhibition on the methanogenic bacterial population is lower compared to the case without inhibition.

From all cases that have been analysed it is evident that the optimal ratio (maximal energy production criterion) of the working volumes of both bioreactors depends of the adopted mathematical model. The choice of the model depends on the used substrates (wastes): in the case of simple waste (e.g. vinasses) simple models are sufficient for process description [20]. In this case the optimal ratio is characterised with high value of $K$, because the reactions rates in the $\mathrm{BR}_{1}$ are very high compared to these in $\mathrm{BR}_{2}$. In the case of more complex substrates (sugars and proteins) more complex models are necessary and the value of $K$ is smaller, because the reactions of hydrolysis and acidogenesis in the $\mathrm{BR}_{1}$ are more complex and their rates are not so high compared to the first case and these in $\mathrm{BR}_{2}$ remaining with the same rates. In the case of very complex substrates (fats and co-digestion of different wastes) much complex models are necessary and the value of $K$ is much smaller (e.g. $K \approx 4$ as in [16]) due to existing of different complex reactions of the hydrolysis and acidogenesis in $\mathrm{BR}_{1}$ and these in $\mathrm{BR}_{2}$ remaining with the same rates. All models and the obtained results concern only the case of CSTRs in the TSAD processes. 


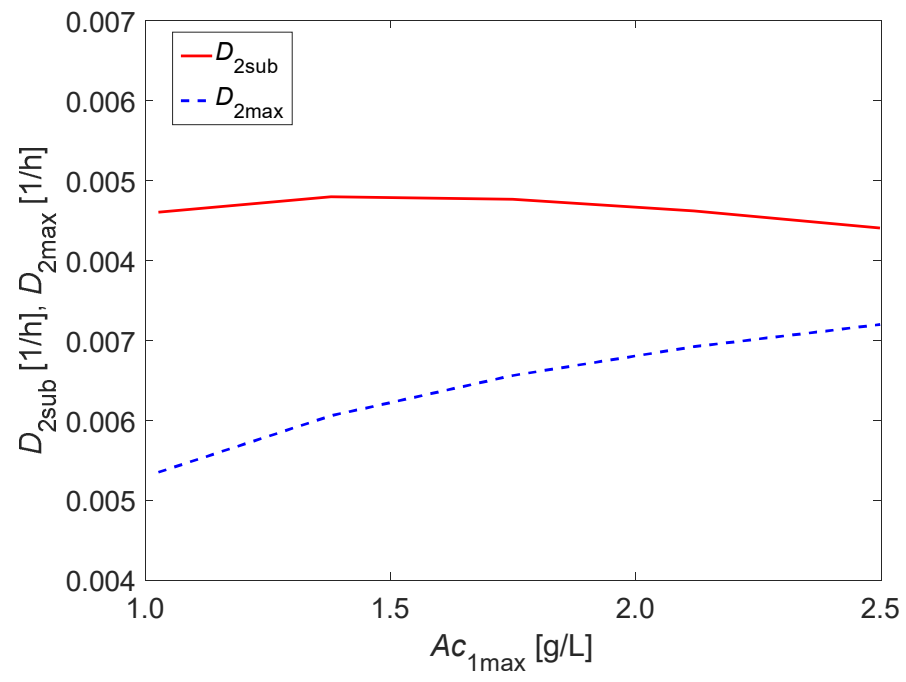

Fig. 9. $D_{2 \text { sub }}$ and $D_{2 \max }$ as a function of $A c_{1 \max }$ for $K_{i}=10$ and $K_{S 2}=0.22$

We could not miss the environmental benefits of biogas technology including anaerobic digestion of lignocellulosic wastes for energy production [17, 21], as a valid sustainable alternative to fossil fuels, so developing appropriate models, characterising these processes is of utmost importance.

\section{Conclusion}

Simple models of the AD of organic wastes for simultaneous production of hydrogen and methane in a two-stage process, including some intermediate products, were developed and their static characteristics were theoretically obtained. A new idea for calculating the optimal ratio of the working volumes of both bioreactors (hydrogenic and methanogenic) based on the operating of both bioreactors in the points of maximal biogas (hydrogen and methane) production is proposed and illustrated with the developed simple models. The obtained results present optimal solutions of the very important problem for practice determination of the optimal ratio (criterion - maximal energy production) of the working volumes of both bioreactors. In all cases the working volume of the hydrogenic $\mathrm{BR}_{1}$ is much smaller than the volume of the methanogenic $\mathrm{BR}_{2}$. This is favourable for large-scale industrial applications where methanogenic BR is existing and investments are smaller.

The obtained input-output static characteristics for the energy carriers hydrogen and methane present maxima for both of them in the admissible range of the control inputs for different values of the main perturbation - inlet substrate concentration in first bioreactor. That is a good possibility for realization of extremum-seeking control algorithms. The optimal ratio (maximal energy production criterion) of the working volumes of both bioreactors depends of the adopted mathematical model that can be applied in real conditions for different substrates such as lignocelluloses wastes (wheat straw). 


\section{Acknowledgements}

The authors gratefully acknowledge the financial support for this work by the Bulgarian National Science Fund, Contract № KP-06-IP China/3.

\section{References}

[1] Gerardi MH. The Microbiology of Anaerobic Digesters. New Jersey: John Wiley Sons, Inc.; 2003. ISBN: 0471250317. Available from: https://www.wiley.com/en-us/9780471206934.

[2] Li Q, Li Y. Coproduction of hydrogen and methane in a CSTR-IC two-stage anaerobic digestion system from molasses wastewater. Water Sci Technol. 2019;79(2):270-7. DOI: 10.2166/wst.2019.042.

[3] Ausiello A, Micoli L, Turco M, Toscano G, Florio C, Pirozzi D. Biohydrogen production by dark fermentation of Arundo donax using a new methodology for selection of $\mathrm{H}_{2}$-producing bacteria. Int $\mathrm{J}$ Hydrogen Energy. 2017;42(52):30599-612. DOI: 10.1016/j.ijhydene.2017.10.021.

[4] Pakarinen OM, Kaparaju PLN, Rintala JA. Hydrogen and methane yields of untreated, water-extracted and acid $(\mathrm{HCl})$ treated maize in one- and two-stage batch assays. Int J Hydrogen Energy. 2011;36:14401-7. DOI: 10.1016/j.ijhydene.2011.08.028.

[5] Ruggeri B, Tommas T, Sanfilippo S. $\mathrm{BioH}_{2} \& \mathrm{BioCH}_{4}$ through Anaerobic Digestion (From research to full-scale applications). London: Springer-Verlag; 2015. Available from: https://www.springer.com/gp/book/9781447164302.

[6] Rafieenia R, Pivato A, Lavagnolo MC. Effect of inoculum pre-treatment on mesopphilic hydrogen and methane production from food waste using two-stage anaerobic digestion. Int J Hydrogen Energy. 2018;43:12013-22. DOI: 10.1016/j.ijhydene.2018.04.170.

[7] Dareioti MA, Kornaros M. Effect of hydraulic retention time (HRT) on the anaerobic co-digestion of agro-industrial wastes in a two-stage CSTR system. Bioresour Technol. 2014;167:407-15. DOI: 10.1016/j.biortech.2014.06.045.

[8] Cavinato C, Bolzonella D, Faton F, Cecchi F, Pavan P. Optimization of two-phase thermophilic anaerobic digestion of biowaste for hydrogen and methane production through reject water recirculation. Bioresour Technol. 2011;102:8605-11. DOI: 10.1016/j.biortech.2011.03.084.

[9] Intanoo P, Rangsanvigit P, Malakul P, Chavadej S. Optimization of separate hydrogen and methane production from cassava wastewater using two-stage upflow anaerobic sludge blanket reactor (UASB) system under thermophilic operation. Bioresour Technol. 2014;173:256-65. DOI: 10.1016/j.biortech.2014.09.039.

[10] Schievano A, Tenca A, Lonati S, Manzini E, Adani F. Can two-stage instead of one-stage anaerobic digestion really increase energy recovery from biomass? Appl Energy. 2014;124:335-42. DOI: 10.1016/j.apenergy.2014.03.024.

[11] Khan MA, Ngo HH, Guo WS, Liu Y, Nghiem LD, Hai FI et al. Optimization of process parameters for production of volatile fatty acid, biohydrogen and methane from anaerobic digestion. Bioresour Technol. 2016;219:738-48. DOI: 10.1016/j.biortech.2016.08.073.

[12] Chorukova E, Simeonov I. Mathematical modelling of the anaerobic digestion in two-stage system with production of hydrogen and methane including three intermediate products. Int $\mathbf{J}$ Hydrogen Energy. 2020;45:11550-8. DOI: 10.1016/j.ijhydene.2019.01.228.

[13] Blumensaat F, Keller J. Modelling of two-stage anaerobic digestion using the IWA Anaerobic Digestion Model No 1 (ADM1). Water Res. 2005;39(1):171-83. DOI: 10.1016/j.watres.2004.07.024.

[14] Hu M, Wang H, Tian Y, Christov N, Simeonov I. On the extremum-seeking control design and application for anaerobic digestion processes. Ecol Eng Environ Protect. 2019;2:23-8. Available from: http://ecoleng.org/archive/2019/2/23-28.pdf.

[15] Simeonov I, Diop S. Stability analysis of some nonlinear anaerobic digestion models. Int J Bioautomation. 2010;14(1):37-48. Available from: https://hal.archives-ouvertes.fr/hal-00544138.

[16] Borisov M, Dimitrova N, Simeonov I. Mathematical modelling and stability analysis of a two-phase biosystem. Processes. 2020;8(7):791. Available from: https://www.mdpi.com/2227-9717/8/7/791.

[17] Paolini V. Environmental impact of biogas: A short review of current knowledge. J Environ Sci Health. Part A. Toxic/Hazardous Substances Environ Eng. 2018;53(10):899-906. DOI: 10.1080/10934529.2018.1459076.

[18] Lara-Cisneros G, Aguilar-López R, Femat R. On the dynamic optimization of methane production in anaerobic digestion via extremum-seeking control approach. Computers Chem Eng. 2015;75:49-59. DOI: 10.1016/j.compchemeng.2015.01.018. 
[19] Andrews JF. A mathematical model for the continuous culture of micro-organisms utilizing inhibitory substrate. Biotechnol Bioeng. 1968;10:707-23. DOI: 10.1002/bit.260100602.

[20] Shan-Fei F, Xiao-Hui X, Meng D, Xian-Zheng Y, Rong-Bo G. Hydrogen and methane production from vinasse using two-stage anaerobic digestion. Process Saf Environ Protect. 2017;107:81-6. DOI: 10.1016/j.psep.2017.01.024.

[21] Cecchi F, Cavinato C. Anaerobic digestion of bio-waste: A mini review focusing on territorial and environmental aspects. Waste Manage Res. 2015;33:429-38. DOI: 10.1177/0734242X14568610. 